\title{
Klänge, Farben, Visionen
}

S. Weiss

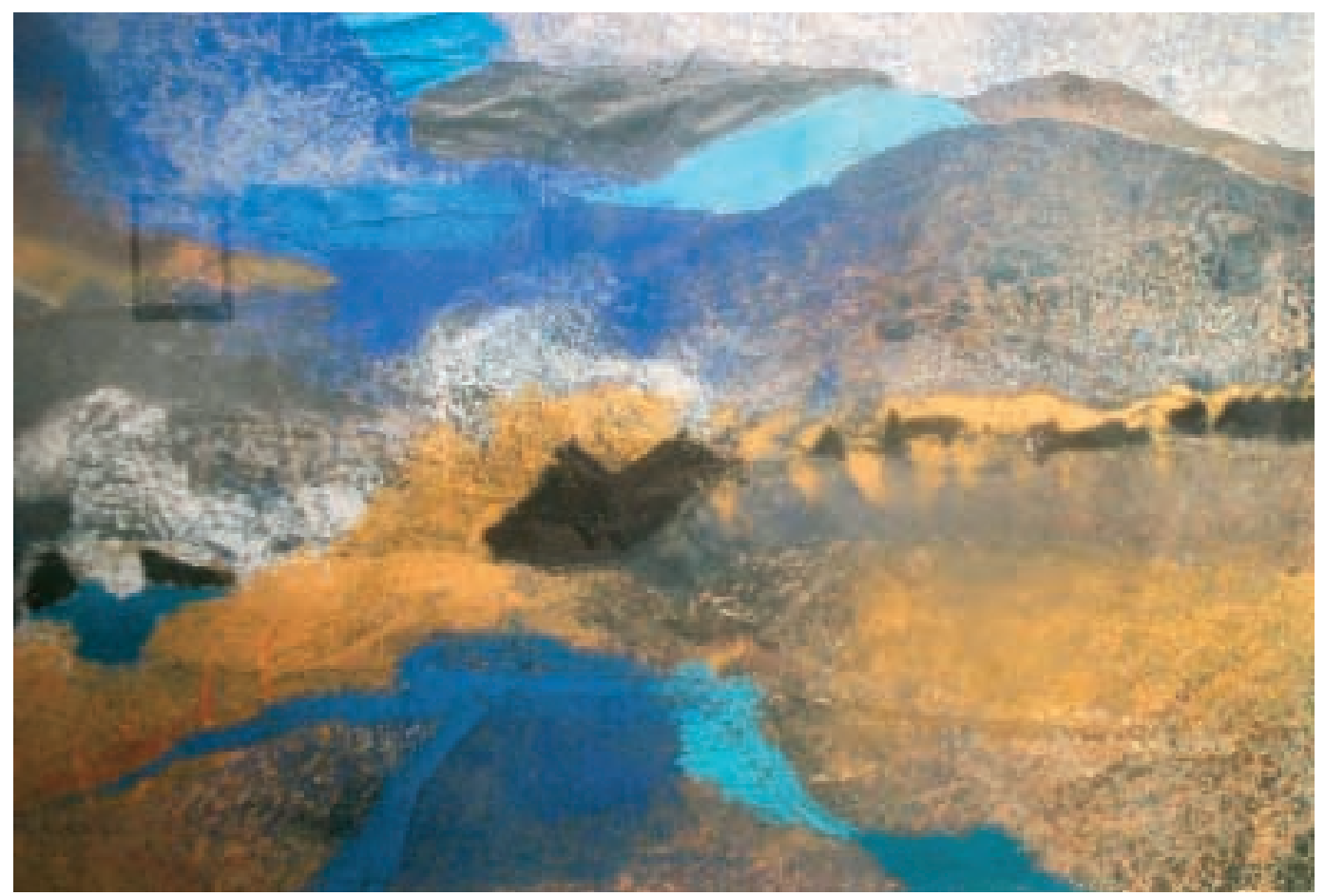

Marianne Ramser, Steffisburg: Ohne Titel (Mischtechnik).

Bereits zum zehnten Mal fand im ehrwürdigen Keller des schönen Rathauses in Murten die Kunstausstellung der Schweizer Ärzte statt (vom 16. bis 30. August 2003).

Die Vereinigung besteht bereits seit 55 Jahren, und es konnten seither jedes Jahr eine oder mehrere Ausstellungen durchgeführt werden.

Wie in den vergangenen Jahren wurde die Ausstellung auch dieses Mal mit einem wunderbaren Konzert unserer Kollegen J. L. Darbellay mit Familie und U. Ammann eingeleitet, das in den stimmungsvollen Gewölben der Französischen Kirche aufgeführt wurde. Das zahlreich erschienene Publikum genoss einmal mehr die abwechslungsreichen, vielseitigen musikalischen Leckerbissen. Mit einer Sonate von J. M. Leclerc begann es im sehr ansprechenden Raum zu tönen und zu klingen. Gedichte von F. Sierra, dargeboten von der rezitierenden Geigerin Noëlle Darbellay, entführten die Zuhörer in moderne Sphären, um mit zwei Liedern unseres Kollegen U. Ammann wieder auf den Boden der Spätromantik zurückzukehren. Ein Höhepunkt war das sehr anspruchsvolle, virtuose Stück «Bach» von J. L. Darbellay für Violinsolo, dargeboten von Francesco Sierra, welches das Publikum mit sehr lange anhaltendem Applaus verdankte. Auch die von unserem Kollegen D. Künzler verfassten und von J. L. Darbellay vertonten Gedichte, die bei diesem Anlass uraufgeführt wurden, erweckten grosse Aufmerksamkeit. Mit einem Haydn-Trio für Violine, Klarinette und Bassetthorn fand das Konzert einen eindrücklichen Abschluss.

An der anschliessenden Vernissage wurden 80 Werke von 25 künstlerisch tätigen Ärztinnen und Ärzten vorgestellt, die ein breites Spektrum von traditionellen Aquarellen, Acrylmalereien und Skulpturen, durchmischt mit sehr modernen Drucken und farbenfrohen Mischtechniken, zeigten.

Eindrückliche Skulpturen aus Holz oder Alabaster leiteten die Besucher vom ersten Raum in den nächsten, so dass harmonisch zusammenpassende, ausgezeichnet beleuchtete Exponate zusammengestellt werden konnten. In diesem Raum fielen farbenfrohe Bilder grossen Formats auf. Überrascht wurde man dann von in der Fensternische ausgestellten feinen Bronzeskulpturen. 


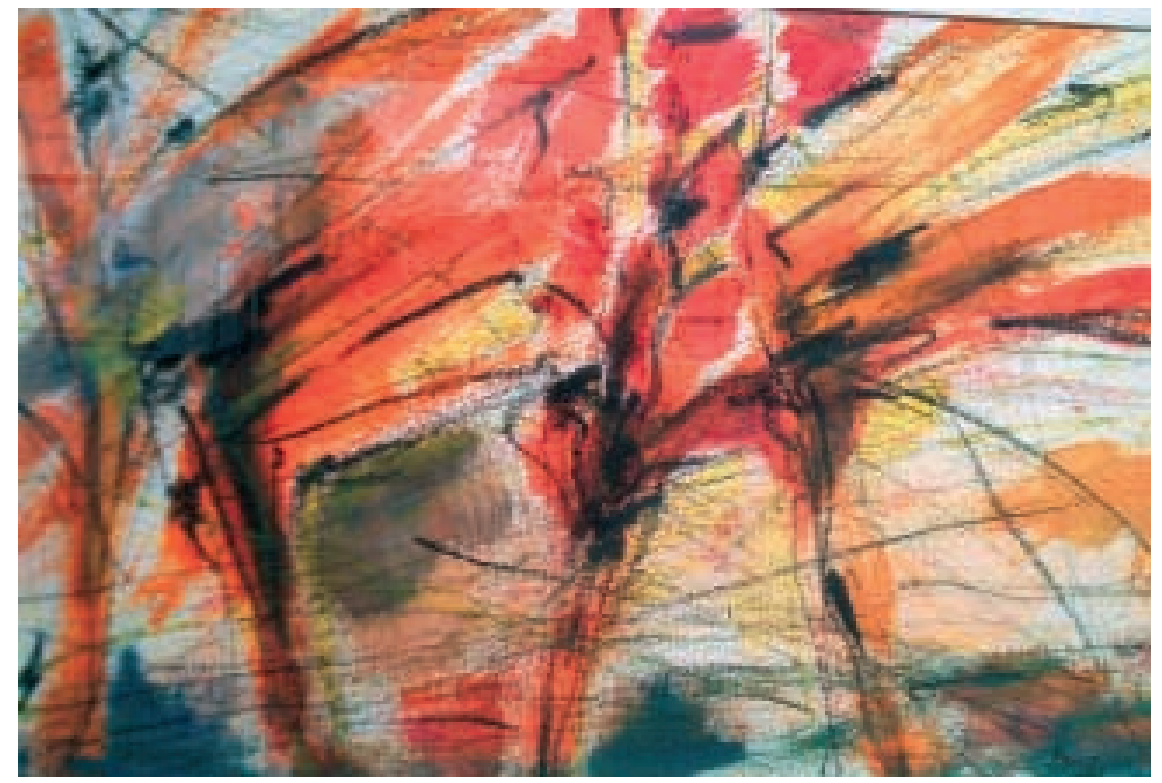

Jardenah Masé-Goldberg, Ziefen: Blumenzauber.

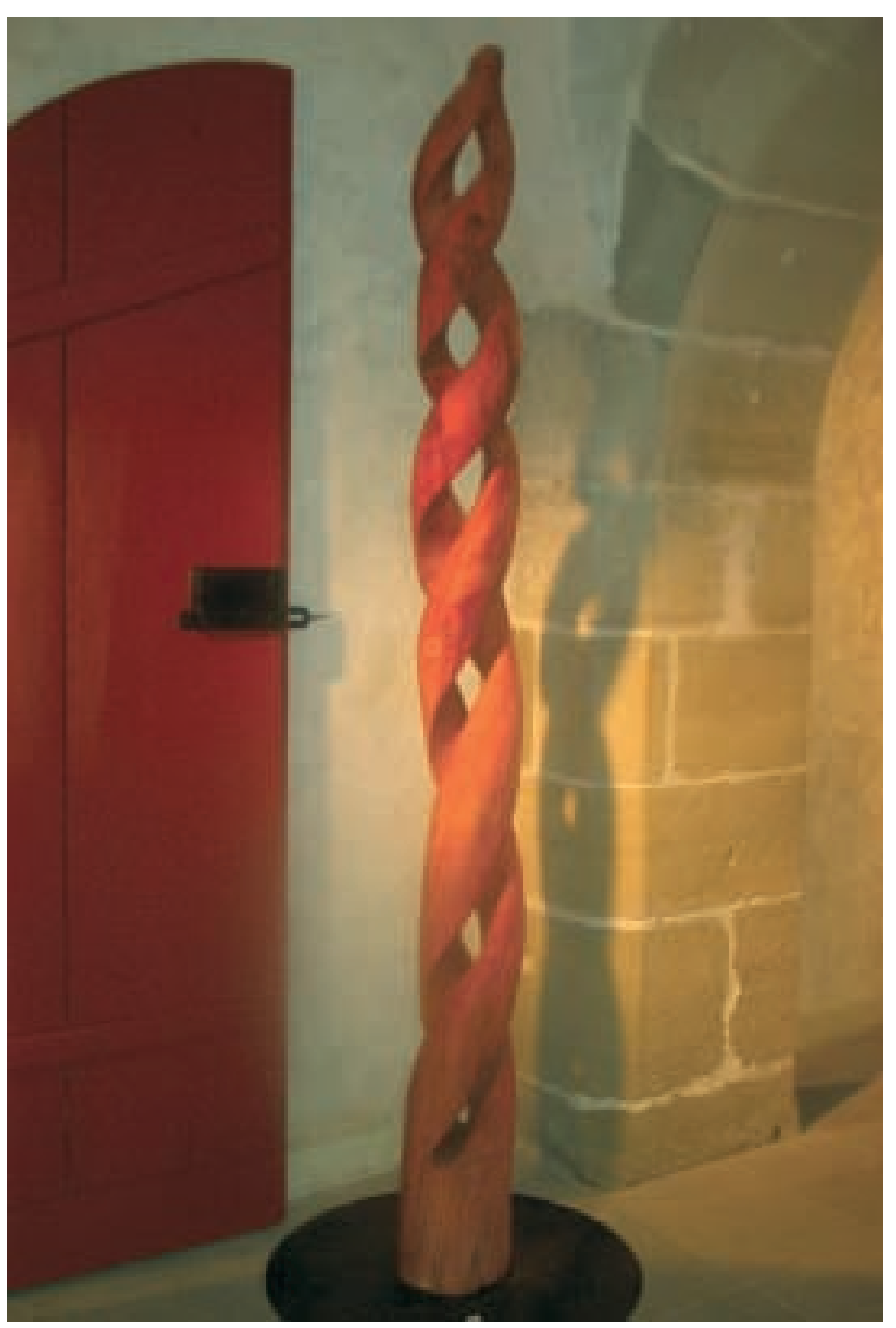

Hansjörg Straumann, Basel: Entwicklung.
Zurück zum hinteren Teil des ersten Raumes, wurde der Betrachter von den «Bildern zum Jahr der Bibel» mit Ikonen, Seidenstickereien und geheimnisvollen Drucken erfreut.

Vor dem Konzert und der Vernissage fand die Jahresversammlung statt, in welcher beschlossen wurde, unsere Vereinigung mit einer Internetseite vor allem bei jungen Kollegen noch besser bekannt zu machen. Zudem wurde angeregt, bei Medizinstudenten für unsere Vereinigung $\mathrm{zu}$ werben.

Falls Sie interessiert sind, zögern Sie nicht, und melden Sie sich an beim Sekretariat Medizinischer Kongressdienst Bäbler, Postfach 109, 3000 Bern 21, Fax 03137170 40, E-Mail:baebler@ mkbverlagmedizin.ch. Weitere Informationen erhalten Sie im Internet unter www.aerztekunst.ch.

Als Mitglieder sind alle Ärztinnen und Ärzte willkommen, die gestalterisch tätig sind (auch kreative Fotografen, Videokünstler usw.!). Ihre Anmeldung plus Einzahlung des Jahresbeitrages von derzeit Fr. 75.- genügen, schon sind Sie dabei und werden bei der nächsten Versammlung offiziell aufgenommen. 

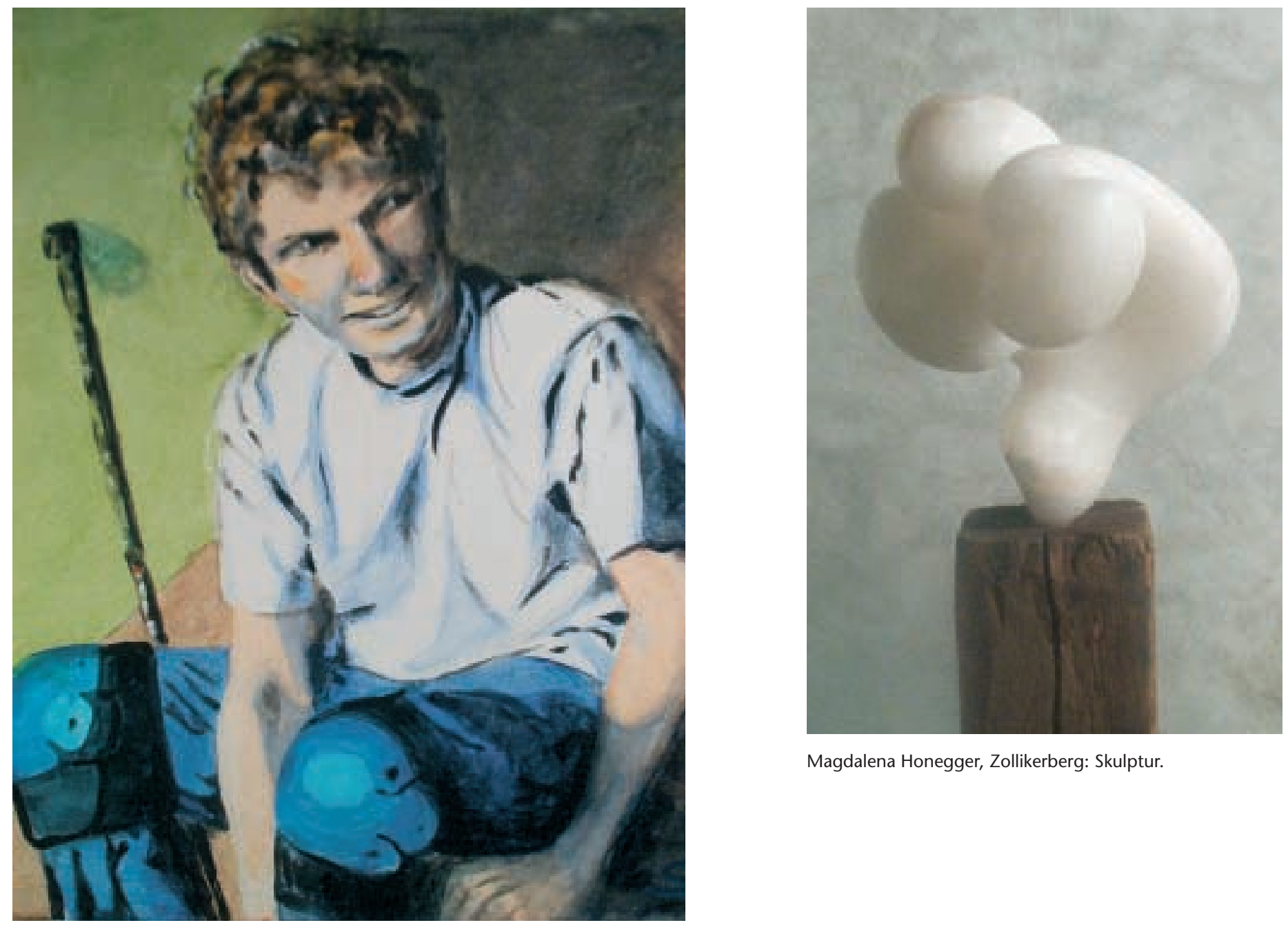

Magdalena Honegger, Zollikerberg: Skulptur.

Susi Dennler, Oetwil: Felix (Mischtechnik).

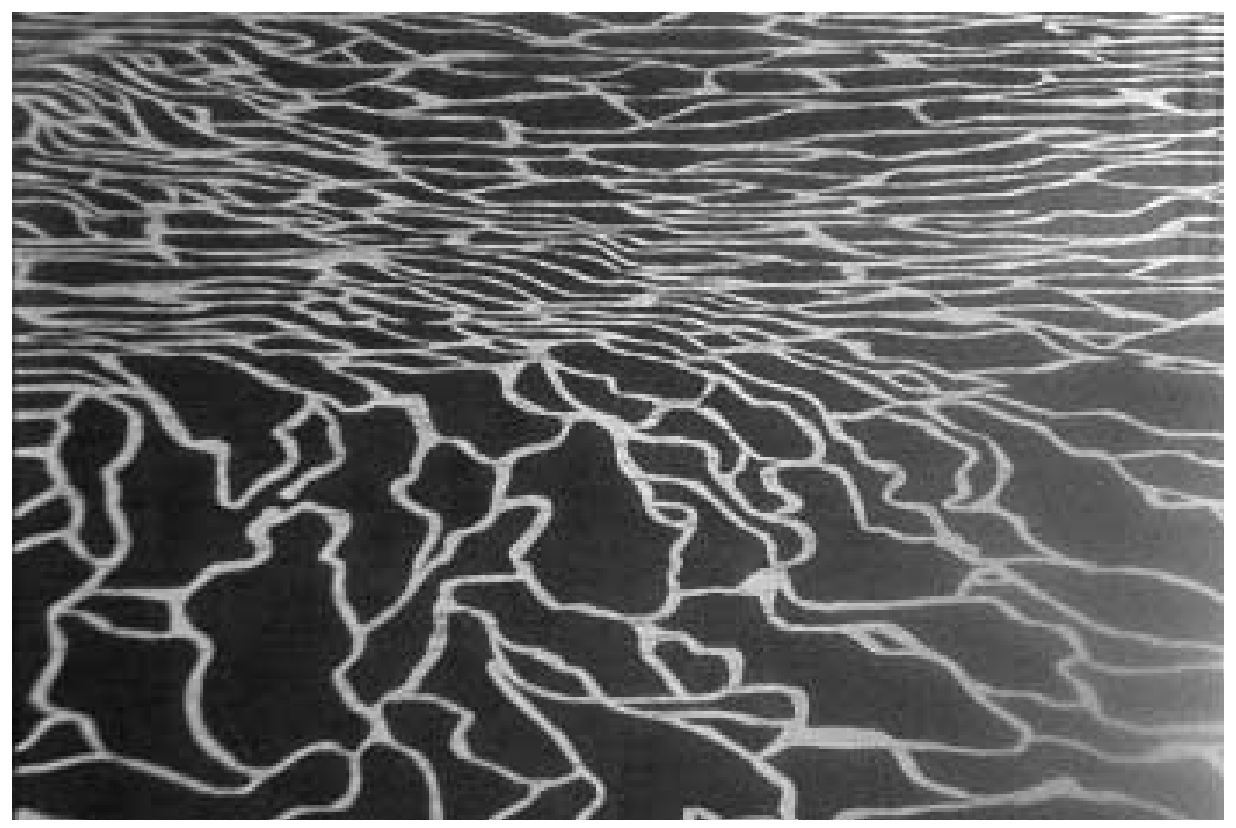

Peter Schluep, Grenchen: Ohne Titel (Holzschnitt). 